Original article

\title{
Are socioeconomic status and type of residence critical risk factors of under-five mortality in Pakistan? Evidence from nationally representative survey
}

\author{
Lubna Naz $^{\mathrm{a}, *}$, Kamalesh Kumar Patel ${ }^{\mathrm{b}}$, Azer Dilanchiev ${ }^{\mathrm{c}}$ \\ ${ }^{a}$ Department of Economics, University of Karachi, Karachi, 75270, Pakistan \\ ${ }^{\mathrm{b}}$ Indian Institute of Health Management Research (IIHMR), Jaipur, 302029, India \\ ' International Black Sea University, David Aghmashenebeli Alley, 13th km, 2, 0131, Tbilisi, Georgia
}

\section{A R T I C L E I N F O}

\section{Keywords:}

Birth interval

Birth size

Cox proportional hazards regression

Socioeconomic status

Type of residence

Under-five mortality

\begin{abstract}
A B S T R A C T
Introduction: Pakistan had the highest mortality rate (75/1000) among under-five children in the South Asia, followed by Afghanistan (68/1000) in 2017. This paper examines whether socioeconomic status and type of residence are crucial risk factors of under-five mortality or not in Pakistan.

Methods: The bivariate and Cox Proportional Hazards regression were applied on a sample of 19,190 under-five children extracted from the Pakistan Demographic and Health Survey 2017-18 to examine the impacts of risk factors on under-five mortality.

Results: The rich families were associated with $28 \%$ reduced risks (HR $=0.72 ; 95 \%$ CI: $0.64-0.81$ ) of under-five mortality compared to the poor, and urban had $19 \%$ a lower risk (HR $=0.81 ; 95 \%$ CI: O.73-0.89) compared to rural (model 1). Educated mothers had 25 lower risk mothers (HR =0.75; 95\% CI:0.60-0.93), mothers aged 18 years and above at first birth had $21 \%$ lower risk (HR $=0.79 ; 95 \% \mathrm{CI}$ : 0.65-0.95); mothers experiencing birth spacing of more than 3 years were associated with $44 \%$ lower risk (HR $=0.56$; 95\% CI: $0.45-0.69)$; average birth size was associated with $36 \%$ lower risk ( $\mathrm{HR}=0.64$; 95\% CI: $0.51-0.78)$, and female child with $11 \%$ reduced risk ( $\mathrm{HR}=0.64 ; 95 \% \mathrm{CI}:$ 0.51-0.78), whereas socioeconomic status and type of residence were not statistically significant (model 2).

Conclusion: The results call for revisiting healthcare policies and propose holistic programs for under-five mortality reduction in Pakistan.
\end{abstract}

\section{Introduction}

In Pakistan, under-five mortality has decreased from 112 per 1000 live births in $1990-91$ to $74 / 1000$ in $2017-18 .^{1}$ A recently published report by the UN Inter Agency Group for Child Mortality Estimation-2015 reported that child mortality declined from 201 (per 1000 live births) in 1968 to 74 in $2017 .^{2}$ The implementation of the series of programs, such as several public health programs such as National Expanded Program of Immunization (EPI), Maternal and Child Health Programs (MNCH), National Program of Control of Diarrheal Disease (CDD), Integrated Management of Childhood Illness Strategy (IMNCI), and Women Health Project (in 20 districts), has contributed in the decline of under-five mortality in Pakistan. ${ }^{3}$

Despite these development in under-mortality reductions, Pakistan has the highest mortality rate $(75 / 1000)$ of under-five children in South Asia, followed by Afghanistan $(68 / 1000)$ in $2017 .{ }^{2}$ This figure is close to 78 deaths per 1000 live births in Sub-Saharan Africa (a region with the highest incidence of under-five deaths worldwide). Moreover, it exceeds the average (41/1000) under-five mortality of South Asian countries in 2018. Achieving a substantial reduction in under-five deaths still remains a daunting challenge in public healthcare policies.

The existing literature provides adequate evidence on various risk factors of childhood mortality, including, low level of maternal education, ${ }^{5-9}$ low economic status of households, ${ }^{10,11}$ and underutilization of healthcare services. ${ }^{12-14}$ The majority of poor people in developing countries are often deprived of basic healthcare services. ${ }^{15-20}$ Moreover, inhabitants from rural areas are more at risk of child death in less developing countries. ${ }^{21}$ It may be because of low coverage of healthcare

\footnotetext{
* Corresponding author.

E-mail addresses: lubnanaz@uok.edu.pk (L. Naz), kamaleshkumar.patel@gmail.com (K.K. Patel), adilanchiev@ibsu.edu.ge (A. Dilanchiev).
} 
in rural or far-flung areas, illiteracy, and social practices hindering population health. ${ }^{22-24}$

In Pakistan, wide differentials exist in under-five mortality across wealth status, and between the rural and urban. ${ }^{1}$ Previous literature have been limited to estimating all potential risk factors of under-five mortality in Pakistan. ${ }^{13,25}$ A few studies have analyzed the socioeconomic and regional differentials in under-five mortality. However, the studies were based on old data set, and did not address the wealth-related differentials in estimating under-five mortality in Pakistan. ${ }^{26-28}$

To our knowledge, present study makes the first attempt to explore whether socioeconomic status and type of residence impact under-five mortality in Pakistan or not by using the most recent Pakistan Demographic and Health survey of 2017-18. To answer the research question, we followed the analytical framework of biological and sociodemographic characteristics of childhood survival ${ }^{29}$

This research is timely in the context of the needed progress towards achieving the Sustainable Development Goals 3 (SDG) and mainly with respect to the target 3.2 which emphases on lowering under-five deaths to 25 per 1000 live births by 2030 . Besides, the SDG 3 calls for tapering rural-urban and wealth differences in child healthcare.

\section{Materials and methods}

\subsection{Data and sample}

This article used the most recent data from the Pakistan Demographic and Health Survey (PDHS) of 2017-18, a nationally representative data set. The sample design of PDHS consists of two-stage stratified random sampling. In the first stage, clusters embeded various enumeration blocks were selected. In total, 580 Primary Sampling Units (PSUs) were chosen. Households in each enumeration block (EBs) were the same ones which had been counted in the Sixth Population and Housing Census in 2017. In the second stage, 28 families from each cluster were systematically chosen. Finally, the interviews were held with 16,240 households.

Altogether 12,364 ever-married women (aged 15-49) who were permanent or de jure member of the households were interviewed. Estimates drawn from the survey are representative of the urban and rural domains, separately. To examine under-five survival, we collected information on birth histories of married women age 15-49 in five years preceding the survey. Specifically, the data was collected on birth records, child deaths, institutional delivery, living children, women's age at first birth, and women's job, and maternal education.

\subsection{Outcome variable}

We followed the UNICEF definition of under-five mortality, that is "the likelihood of dying between the birth and exactly five years of age denoted per 1000 live births". ${ }^{4}$ We used data on birth histories of women age 15-49, and death records of children (age 0-59 months) of five years preceding the survey. The dependent variable was a hazard ratio (relative risk) of death in the age ranging from birth (0) to 59 months.

\subsection{Household-related risk factors}

The literature suggests that a myriad of factors influence a child survival, including wealth, education, occupation, income, consumption, accessibility to credit, and social networks. ${ }^{17,30,31}$ In Pakistan, a paltry female labor force participation, a large number of unpaid-workers, subsistence livelihood, high share of informal earnings, and inadequate information on access to credit make it difficult to develop the multidimensional construct of socioeconomic well-being. ${ }^{32-35}$ Therefore, the present study used household wealth index as an indicator of socioeconomic status, which synchronizes with the available literature. ${ }^{36}$ The PDHS-2017-18 collected information on 29 household assets, comprising consumer durables, transporting vehicles, agricultural land, and selected farm animals of 11,869 households. A Principle Component Analysis (PCA) technique was employed to construct household wealth scores by combining the household possessions. Finally, the aggregated wealth scores were divided into five equivalent groups, representing twenty percent in each group. ${ }^{37}$ The present article regrouped wealth quintiles into three following categories, poor, middle and rich, and named it "socioeconomic status". The lowest group (poor) comprised poorest and the poor, and the highest included both rich and richest.

The PDHS 2017-18 reports an overwhelming effect of household wealth on healthcare needs in Pakistan. For example, only $9 \%$ of births were registered in the poorest households whereas $78 \%$ belonged to the richest quintile. It also reveals a wide variation in the institutional delivery across socioeconomic background. The poorest families showed up the lowest rate of institutional delivery (41\%) as compared to middle (69\%) and the wealthiest (92\%). Around two-third of children in the richest households received all recommended vaccinations, whereas in poor families only $27 \%$ children received the vaccination in 2017-18.

We measured household's type of residence as a categorical variable, see Table 1. The PDHS 2017-18 showed fluctuations in the under-five deaths across the rural and urban households in Pakistan. The rural families depicted more child mortality (83 for every 1000 live births) than the urban (56) in last five years' prior the current survey. Moreover, the child mortality among rural households (79 per 1000 livebirths) was over and above the national average. ${ }^{1}$

\subsection{Mother-related risk factors}

We included maternal education as one of the risk factors in the study and categorized it as follows: educated and not-educated (Table 1). The educated category includes mothers who had primary and above education, and uneducated implies mothers without any education. The PDHS 2017-18 shows that mothers with secondary and above education comprises a small proportion (38\%) of the sample Therefore, we merged primary education with secondary and above. Previous research indicates that maternal education has significantly

Table 1

Description of risk covariates of under-five mortality in Pakistan.

\begin{tabular}{|c|c|c|}
\hline Variables & $\begin{array}{l}\text { Measurement } \\
\text { scale }\end{array}$ & Description \\
\hline \multicolumn{3}{|l|}{ Outcome variable } \\
\hline $\begin{array}{l}\text { Under-five } \\
\text { mortality }\end{array}$ & Binary & $\begin{array}{l}=1 \text { If child had died between birth and } \\
\text { fifth birthday in five years preceding the } \\
\text { survey; } 0 \text { otherwise }\end{array}$ \\
\hline \multicolumn{3}{|l|}{ Mother-related } \\
\hline Mother's education & Categorical & $\begin{array}{l}\text { Educated }=1 \\
\text { Not-educated }=2\end{array}$ \\
\hline $\begin{array}{l}\text { Mother's } \\
\text { employment }\end{array}$ & Binary & $\begin{array}{l}\text { working }=0 \\
\text { Not-working }=1\end{array}$ \\
\hline Birth interval & Categorical & $\begin{array}{l}<2 \text { years }=1 \\
2-3 \text { years }=2 \\
>3 \text { years }=3\end{array}$ \\
\hline $\begin{array}{l}\text { Institutional } \\
\text { delivery }\end{array}$ & Categorical & $\begin{array}{l}\text { Yes }=1 \\
\text { No }=2\end{array}$ \\
\hline $\begin{array}{l}\text { Mother's age at } \\
\text { first birth }\end{array}$ & Categorical & $\begin{array}{l}18 \text { years }>=\text {, age }=1 \\
18 \text { years }<\text { age }=2\end{array}$ \\
\hline \multicolumn{3}{|l|}{ Child-Related } \\
\hline Sex of the child & Categorical & $\begin{array}{l}\text { Male }=1 \\
\text { Female }=2\end{array}$ \\
\hline Birth size & Categorical & $\begin{array}{l}\text { Small }=1 \\
\text { Average }=2 \\
\text { Large }=3\end{array}$ \\
\hline \multicolumn{3}{|l|}{ Household-related } \\
\hline $\begin{array}{l}\text { Socioeconomic } \\
\text { status }\end{array}$ & Categorical & $\begin{array}{l}\text { Poor }=1 \\
\text { Middle }=2 \\
\text { Rich }=3\end{array}$ \\
\hline Type of residence & Categorical & $\begin{array}{l}\text { Rural }=1 \\
\text { Urban }=2\end{array}$ \\
\hline
\end{tabular}


contributed to maintain the nutritional status of children which in turn determines the survival hood of children $(4-6,20)$.

PDHS 2017-18 provides information on mothers who were engaged in some gainful employment at the time of survey. We used mother's current working status as a binary variable $(0 / 1)$, see Table 1 .

The present study utilized the information given by PDHS 2017-18 on institutional arrangements of child birth. We used the data on whether a married woman aged 15-49 had used institutional facility in giving the most recent birth or not. Various responses, such as giving birth at hospital, clinic, rural health unit, basic health facility etc. were combined into a single option i.e., institutional delivery or otherwise, see Table 1. Mother' age at first delivery was a categorical variable, mothers who were below 18 years of age at first birth were coded as 1 , and older than 18 years were coded as 2 . Birth-interval was categorized (excluding first birth) as follows, $<2$ years, $2-3$ years, and $>3$ years, see Table 1 . The orderings were formed following the guideline of the World Health Organization (WHO), which recommends mothers to adhere to the birth spacing of 3-5 years to lessen the survival risk among newborns and mothers.

\subsection{Child-related risk factors}

Birth size is considered as a potential risk factor for the child mortality. ${ }^{12,14,38}$ The survey (PDHS 2017-18) collected information from mothers on the birth size of the most recently born children. Each mother was asked to recall and respond with options ranging from very large birth size to the smallest based on their perception about the size of child at the time of child's birth. ${ }^{1}$ For this study, birth size was ere regrouped, as follows, small, average, and large.

\subsection{Cox Proportional Hazards regression}

All variables used in the present article were either categorical or binary. So, we used Chi-square test to evaluate associations between risk factors and under-five mortality using three significance levels, p-value $<0.001$, p-value $<0.05$, and p-value $<0.01$. We used the Cox Proportional Hazards regression to analyze the impacts of risk factors on underfive mortality. ${ }^{39}$ Firstly, we measured the effects of socioeconomic status and type of residence on under-five mortality. Secondly, we included confounding risk factors, mother and child-related, along with wealth status and type of residence in the model. The following specification was used,

$h_{i}(t, X)=h_{0}(t)+\exp \left(\varphi X_{1}+\varphi X_{2} \ldots \ldots, \varphi X_{n}\right)$

$h_{i}(t, X)$ is the hazard or risk of death for the ith child at the time $t$, $h_{0}(t)$ is the risk (a time varying intercept term) at time $t . X=$ $\left(x_{1}+x_{2}+\ldots,+x_{n}\right)$ are risk factors, and $\phi 1, \phi 2, \ldots, \phi n$ are coefficients of crucial factors to be estimated. The Cox model presumes that the risk of death to any ith child (who is under-five years age) is proportional to the hazard pertaining to any $j$ th child. It is equivalent to the constant HR (relative risk) over time $t$. If the value of $X_{i}$ is assumed to be zero; the hazard function tends to be the baseline hazard function. If $X_{i}$ takes on any value except zero, we can obtain the hazard ratio by dividing equation (2) by $h_{0}(t)$ and applying logarithm as follows,

$\ln \left[\frac{h_{i}(t)}{h_{0}(t)}\right]=\phi_{1} X_{1}+\phi_{2} X_{2}+, \ldots \ldots+\phi_{n} X_{n}$

The HR in equation (2) is the likelihood of an event (death) in one group of a factor to the probability of occurring the event in other groups. HR $>1$ implies increased hazard of under-five deaths, $\mathrm{HR}<1$ signifies decreased risk of under-five mortality, and HR equals to 1 means no effect at all. The estimation was executed in Stata 15. The Cox regression used in the paper is robust to the sample selection bias compared to a simple logit model.

\section{Results}

\subsection{Bivariate analysis}

The results are based on a sample of 19,190 of live births, of which 1512 deaths of under-five children occurred in five years preceding the survey. The under-five deaths were highest among the poor households (85/1000 live births), followed by middle (76/1000), and lowest among the rich $(56 / 1000)$. The rural residents had a greater prevalence of under-five mortality $(79 / 1000)$ than that of the urban counterparts (61/ 1000) (Table 2).

The mother-related factors, except institutional delivery, were statistically significant and related with the under-five mortality. However, the under-five mortality was higher (90/1000) among younger mothers (below 18 years of age). The prevalence rates were also higher among working (98/1000) and uneducated (87/1000) mothers. Short birth interval ( $<2$ years) was associated with a higher prevalence $(112 / 1000)$ of under-five mortality compared to birth-spacing spanning 2-3 years, and above 3 years. Amongst child-related factors, sex of the child, and birth size showed a statistically significant association with the underfive death. The small birth size was associated with a larger prevalence of under-five mortality (88/1000) compared to average and large sizes (Table 2).

\subsection{Multivariate analysis}

The results of both socioeconomic status and type of residence

Table 2

The under-five mortality by mother, child, and household-related risk factors in Pakistan.

\begin{tabular}{|c|c|c|c|}
\hline \multirow[t]{2}{*}{ Risk factors } & \multicolumn{3}{|c|}{ Under-five child mortality (per 1000 live births) } \\
\hline & $\mathrm{N}$ & Under-five deaths & $\mathrm{p}$-value \\
\hline \multicolumn{4}{|l|}{ Mother-related } \\
\hline \multicolumn{4}{|c|}{ Mother's education } \\
\hline Not-Educated & 949 & 87 & $\mathrm{p}<0.001$ \\
\hline Educated & 563 & 58 & \\
\hline \multicolumn{4}{|c|}{ Mother's employment } \\
\hline Not-Working & 1114 & 67 & $\mathrm{p}<0.001$ \\
\hline Working & 398 & 98 & \\
\hline \multicolumn{4}{|c|}{ Institutional delivery ${ }^{\mathrm{a}}(N=685)$} \\
\hline No & 256 & 73 & 0.047 \\
\hline Yes & 429 & 63 & \\
\hline \multicolumn{4}{|c|}{ Birth Interval ${ }^{\mathrm{b}}(N=1144)$} \\
\hline$<2$ years & 774 & 112 & $\mathrm{p}<0.001$ \\
\hline $2-3$ years & 196 & 43 & \\
\hline$>3$ years & 174 & 40 & \\
\hline \multicolumn{4}{|l|}{ Age at first birth } \\
\hline$<18$ years & 489 & 90 & $\mathrm{p}<0.001$ \\
\hline$>=18$ years & 1023 & 67 & \\
\hline \multicolumn{4}{|l|}{ Child-related } \\
\hline \multicolumn{4}{|l|}{ child sex } \\
\hline Male & 874 & 83 & $\mathrm{p}<0.001$ \\
\hline Female & 638 & 62 & \\
\hline \multicolumn{4}{|c|}{ Birth size ${ }^{a}(N=682)$} \\
\hline Small & 171 & 88 & $\mathrm{p}<0.001$ \\
\hline Average & 467 & 61 & \\
\hline Large & 45 & 59 & \\
\hline \multicolumn{4}{|c|}{ Household-related } \\
\hline \multicolumn{4}{|c|}{ Socioeconomic status } \\
\hline Poor & 785 & 85 & $\mathrm{p}<0.001$ \\
\hline Middle & 326 & 76 & \\
\hline Rich & 401 & 56 & \\
\hline \multicolumn{4}{|c|}{ Type of residence } \\
\hline Rural & 1104 & 79 & $\mathrm{p}<0.001$ \\
\hline Urban & 408 & 61 & \\
\hline Total & 1512 & 73 & \\
\hline
\end{tabular}

${ }^{\mathrm{a}}$ Information available for only recent birth.

${ }^{\mathrm{b}}$ Excluding first birth. 
showed statistically significant effects on under-five mortality, see model 1 (Table 3). Rich families were associated with $28 \%$ reduced hazards of under-five child mortality compared to the poor $(\mathrm{HR}=0.72$; 95\% CI: $0.64-0.81$ ). The relative risk of death was $9 \%$ lower for the middle, though, the result was not statistically significant. The cumulative survival rates of children for the poor, middle and the rich are compared in Fig. 1.

The urban households had lower risk (19\%) of under-five death than their rural counterparts ( $\mathrm{HR}=0.81$; 95\% CI: O.73-0.89). A rural versus urban comparison of survival rates of under-five children is shown in Fig. 2.

The mother-related factors (except institutional delivery) hads impacts on child mortality. Children whose mothers were adequately educated had a lower likelihood of dying before reaching the fifth birthday than those of uneducated mothers ( $\mathrm{HR}=0.75 ; 95 \%$ CI:0.60-0.93).

The working mothers were associated with higher (1.25 times) hazards of under-five mortality compared to not-working mothers (HR $=1.25$; 95\% CI: $1.00-1.06$ ). Women aged 18 years and above at the time of first birth had $21 \%$ lower risk than their younger counterparts (HR = 0.79; 95\% CI: 0.65-0.95). The birth interval and under-five survival were negatively associated. A birth spacing of 2-3 years, and exceeding 3 years were related to $43 \%$ and $44 \%$ (HR $=0.57 ; 95 \%$ CI:0.46-0.71; $\mathrm{HR}=0.56$; $95 \% \mathrm{CI}$ : 0.45-0.69) of decreased risk of under-five mortality.

The female child had lesser probability of dying (11\%) before completing five years of age compared to a male child ( $\mathrm{HR}=0.89 ; 95 \%$ CI: $0.75-1.01)$. The average birth size predisposes the child to a lower risk (36\%) of mortality relative to small ( $\mathrm{HR}=0.64$; 95\% CI: $0.51-0.78$ ). Large birth size was not significantly associated with under-five

Table 3

The results of Cox proportional regression of under-five mortality and associated risk factors in Pakistan.

\begin{tabular}{|c|c|c|c|c|}
\hline \multirow[t]{2}{*}{ Risk factors } & \multicolumn{2}{|l|}{ Model 1} & \multicolumn{2}{|l|}{ Model 2} \\
\hline & HR & $\mathrm{CI}$ & HR & $\mathrm{CI}$ \\
\hline \multicolumn{5}{|c|}{ Mother-related } \\
\hline \multicolumn{5}{|c|}{ Mother's education } \\
\hline Not Educated & & & 1.00 & \\
\hline Educated & & & $0.75^{* * *}$ & $(0.60-0.93)$ \\
\hline \multicolumn{5}{|c|}{ Mother's employment } \\
\hline Not Working & & & 1.00 & \\
\hline Working & & & $1.25^{*}$ & (1.00-1.06) \\
\hline \multicolumn{5}{|c|}{ Institutional delivery } \\
\hline No & & & 1.00 & \\
\hline Yes & & & 1.16 & (0.95-1.39) \\
\hline \multicolumn{5}{|l|}{ Birth interval } \\
\hline$<2$ years & & & 1.00 & \\
\hline $2-3$ years & & & $0.57^{* * *}$ & $(0.46-0.71)$ \\
\hline$>3$ years & & & $0.56^{* * *}$ & $(0.45-0.69)$ \\
\hline \multicolumn{5}{|c|}{ Age at first birth } \\
\hline$<18$ years & & & 1.00 & \\
\hline$>=18$ years & & & $0.79^{* * *}$ & $(0.65-0.95)$ \\
\hline \multicolumn{5}{|l|}{ Child-related } \\
\hline \multicolumn{5}{|l|}{ child sex } \\
\hline Male & & & 1.00 & \\
\hline Female & & & $0.89 *$ & $(0.75-1.01)$ \\
\hline \multicolumn{5}{|l|}{ Birth size } \\
\hline Small & & & 1.00 & \\
\hline Average & & & $0.64^{* * *}$ & $(0.51-0.78)$ \\
\hline Large & & & 0.57 & (0.54-1.09) \\
\hline \multicolumn{5}{|c|}{ Household-related } \\
\hline \multicolumn{5}{|c|}{ Socioeconomic status } \\
\hline Poor & 1.00 & & 1.00 & \\
\hline Middle & 0.91 & $(0.80-1.01)$ & 0.97 & $(0.75-1.23)$ \\
\hline Rich & $0.72^{* * *}$ & $(0.64-0.81)$ & 0.91 & (0.69-1.19) \\
\hline \multicolumn{5}{|c|}{ Type of residence } \\
\hline Rural & 1.00 & Ref. & 1.00 & \\
\hline Urban & $0.81^{* * *}$ & $(0.73-0.89)$ & 0.85 & $(0.69-1.04)$ \\
\hline
\end{tabular}

survival.

The socioeconomic status and type of residence did not show a statistically significant association with child mortality in the Cox regression estimated with confounding factors (model 2). The magnitude of risks for the middle and rich also tend to be lower in the model 2; the rich had $9 \%$ reduced hazard compared to the poor, whereas in model 1, it was $28 \%$ lower for the rich. Hence, it can be concluded that other risk factors, i.e., birth-interval, birth size and mother's education were likely to confound the impacts of socioeconomic status and the type of residence on under-five survival in Pakistan.

\section{Discussion}

The results of this article highlight the leading risk factors of child mortality in Pakistan. The wealthy households had $28 \%$ reduced risk to under-five mortality, and the urban households had 19\% decreased hazards of under-five mortality compared to the reference group. A study from Kazakhstan also reported that households in the lowest and the second-lowest wealth quintiles have 2.7 times and 2.6 times more risks of child mortality than that of the top most quintile. ${ }^{40}$ Our study suggested that children born in urban families were lesser exposed to hazards of under-five death than of rural-children in Pakistan. Several studies from the South Asia revealed the rural-urban differences in the child survival. The gap was attributed mainly due to poor infrastructure, limited outreach of healthcare interventions, lower women autonomy, and illiteracy. ${ }^{22,23,28,41}$

Moreover, the present paper found maternal education as a leading risk factor of under-five mortality. Children born to educated mothers were associated with reduced likelihood of under-five deaths than their counterparts. The result is consistent with previous research findings which highlighted the negative association of maternal education with childhood mortality in developing countries. ${ }^{5-8,42}$ Our research findings offer support to "Chicago-Columbia hypothesis" which states that female education increases female efficiency in the production of child health. ${ }^{43}$

In this study, age of mother at the first delivery was found to be associated with a considerable risk of the survival of under-five children. The children of mothers below 18 years of age were more susceptible to under-five death than those born to older mothers. The findings confirm with the already established evidence that children of older women ( $>35$ years) have a reduced risk of under-five mortality than younger women in Pakistan and Indonesia. ${ }^{13}$

The finding of our study supported that female child had the reduced risk of under-five mortality in Pakistan. It is in conformity with the earlier evidence. ${ }^{13,27}$ The results of our study suggest that wider birth-interval (three years and more) was associated with lower risks of under-five deaths. A similar study found that the birth spacing of 24-35 months was probable to reduce under-five death by $15 \%$ in Pakistan. ${ }^{25}$ Another research from Pakistan suggested that a birth spacing of 24-35 months could probably reduce under-five death by $15 \%{ }^{25}$ The present paper found a negative relationship between currently working mothers and the survival rate of under-five children. The results confirm the proven hypothesis that working mothers allocate lesser time to child healthcare needs which subsequently increases the risk of death among under-five children. ${ }^{44,45}$ However, our research findings did not imply about the occupational status of women, which is an indispensable determinant of child healthcare. Furthermore, previous research has revealed that children born to mothers employed in white-collar jobs, and those mothers who are at managerial positions had a lower risk of dying before the age of five. The lower risk was ascribed to increased female empowerment and its repercussions on the well-being of the child. $^{26}$

This paper has some limitations. The wealth index was employed as a proxy of socioeconomic position. The composite asset and housing index may not reveal the individual effects of specfic household possessions and housing services. Further, it is not a multidimensional construct. 


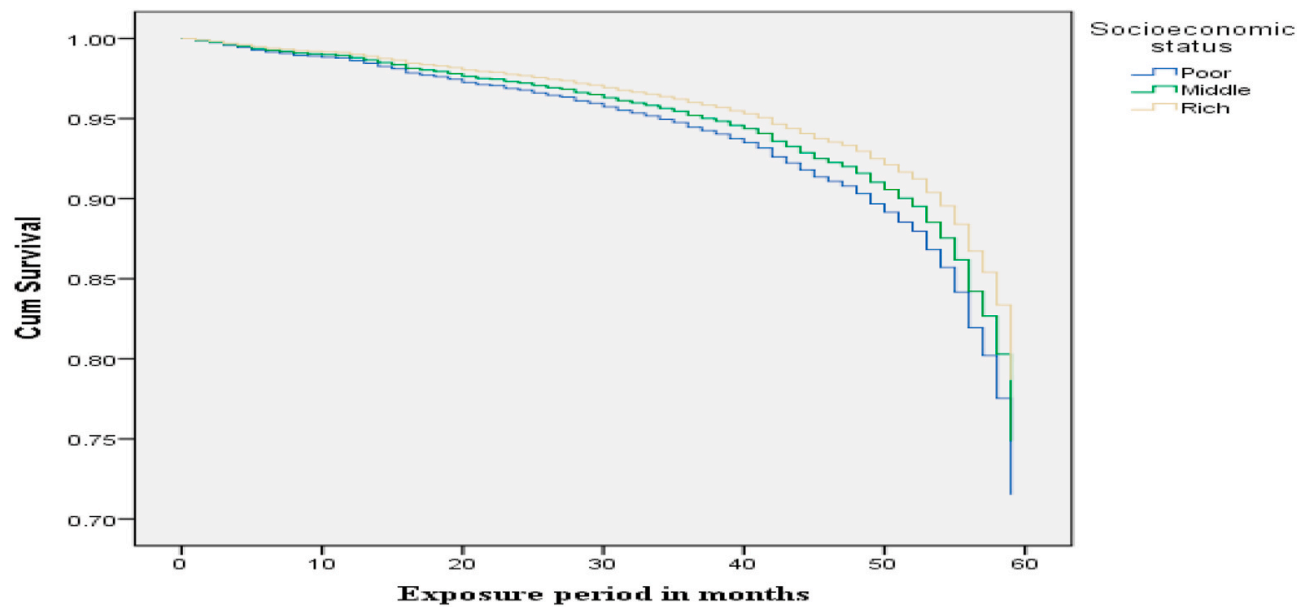

Fig. 1. Cumulative Child Survival by Socioeconomic Status.

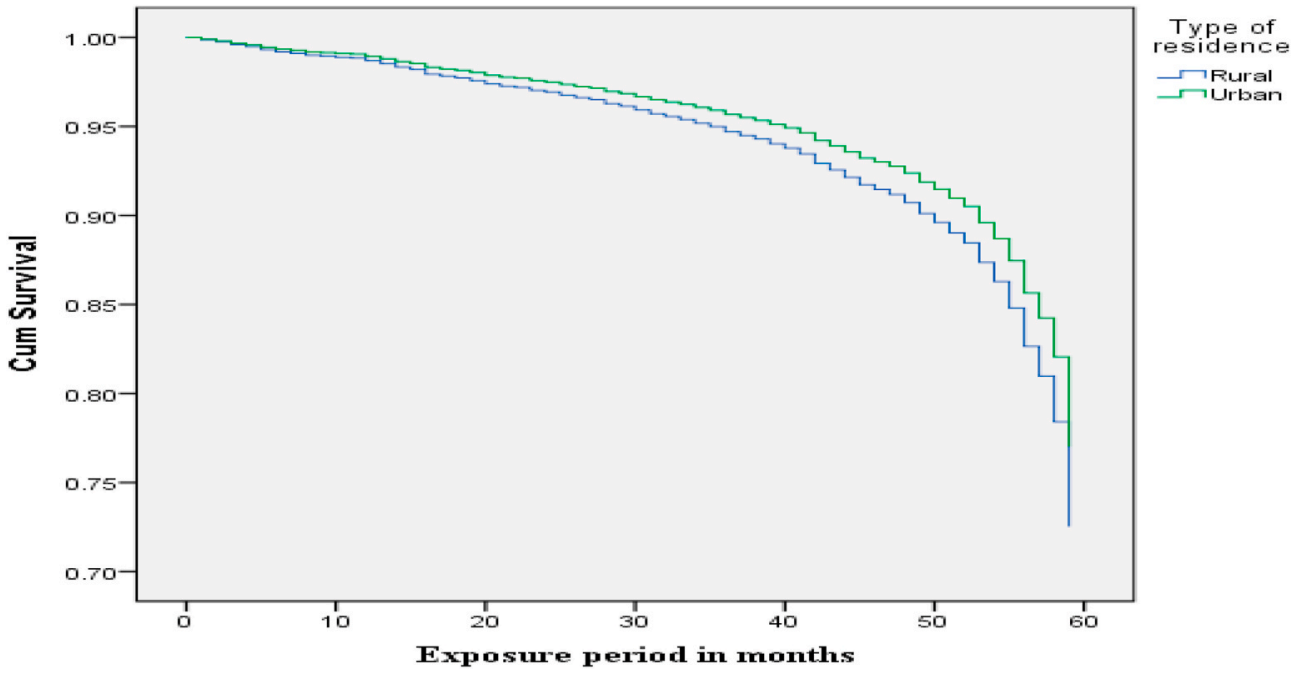

Fig. 2. Cumulative Child Survival by Type of Residence.

The unavailability of the data on income, neighborhood characteristics, and indicators of health make it difficult to formulate a more comprehensive index of well-being. Therefore, information revealed through the wealth index may be inadequate to infer about the welfare of households. We considered only singleton births for assessing the relative risk of dying in the early periods of childhood. Whereas analogous studies have found that multiple births are closely associated with the hazards of infant death.

\section{Conclusions}

This study explores into whether socioeconomic status and type of residence are critical risk factors of under-five mortality in Pakistan or not. It uses the most recent Pakistan Demographic and Health Survey 2017-18, which is a nationally representative data set. The Cox Proportional Hazards regression was used. At first, we analyzed the effects of socioeconomic status and type of residence on under-five mortality, model. Second, we analyzed an extended model, comprising mother, child, and household-related risk factors. Results indicate reduced hazards of under-five deaths in rich families, and the urban. However, both socioeconomic status and type of residence did not show statistically significant relationship with under-five mortality when other confounding risk factors were included in the model. Mother's education, birth spacing, and child birth size showed negative impacts on under- five mortality in Pakistan. A careful review of the current healthcare and poverty reduction programs indicate the prime focus of these programs is on removing socioeconomic and regional inequalities in maternal and child healthcare. ${ }^{3,27,32}$ Results of this study call for revisiting child healthcare policies and propose holistic programs for under-five mortality reduction in Pakistan.

\section{Funding/Financial support}

Authors have not received any funding from any organization to carry out this research.

\section{Acknowledgement}

The data supporting this manuscript is available publicly on the website of the DHS program (USAID). We would like to acknowledge the DHS program-USAID for providing us access to download the Pakistan Demographic Health Survey from its website. The following is the link of Pakistan Demographic Health survey used in this manuscript. https:// dhsprogram.com/data/dataset_admin/index.cfm.

\section{References}

1 National Institute of Population Studies. Pakistan demograhic and health survey. http://nips.org.pk/abstract_files/PDHS 2017-18 - key findings.pdf; 2018. 
2 UNICEF. Key demographic indicators. https://data.unicef.org/country/afg/; 2017.

3 Shoukat M, Khurmi M, Fahim UM. Child health status in Pakistan. J Ayub Med Coll Abbottabad. 2015;1(1):21-23.

4 UNICEF. Levels \& Trends. Child Mortality: Report 2019-Estimates Developed by the UN Inter-agency Group for Child Mortality Estimation. Unicef/Who/Wb/Un; 2019. https:// doi.org/10.1371/journal.pone.0144443.

5 Bicego GT, Boerma JT. Maternal education and child survival: a comparative study of survey data from 17 countries. Soc Sci Med. 1993;36(9):1207-1227.

6 Chen Y, Li H. Mother's education and child health: is there a nurturing effect? $J$ Health Econ. 2009;28(2):413-426. https://doi.org/10.1016/j. jhealeco.2008.10.005.

7 Cleland JG, van Ginneken JK. Maternal education and child survival in developing countries: the search for pathways of influence. Soc Sci Med. 1988;27(12): 1357-1368. https://doi.org/10.1016/0277-9536(88)90201-8.

8 Das Gupta M. Death clustering, Mothers' education and the determinants of child mortality in rural Punjab, India. Popul Stud. 1990;44(3):489-505. https://doi.org/ 10.1080/0032472031000144866.

9 Glewwe P. Why does mother's schooling raise child health in developing countries? Evidence from Morocco. J Hum Resour. 1999;34(1):124-159. https://doi.org/ $10.2307 / 146305$.

$10 \mathrm{Pal}$ S. An analysis of childhood malnutrition in rural India: role of gender, income and other household characteristics. World Dev. 1999;27(7):1151-1171. https://doi org/10.1016/S0305-750X(99)00048-0.

11 Lartey ST, Khanam R, Takahashi S. The impact of household wealth on child survival in Ghana. J Health Popul Nutr. 2016;45(38). https://doi.org/10.1186/s41043-0160074-9.

12 Maitra P. Parental bargaining, health inputs and child mortality in India. $J$ Health Econ. 2004;23(2):259-291. https://doi.org/10.1016/j.jhealeco.2003.09.002.

13 Martin LG, Trussell J, Salvail FR, Shah NM. Co-variates of child mortality in the Philippines, Indonesia, and Pakistan: an analysis based on hazard models*. Popu Stud. 1983;37(3):417-432. https://doi.org/10.1080/00324728.1983.10408870.

14 Panis CWA, Lillard Lee A. Health inputs and child mortality: Malaysia. J Health Econ 1994;13(4):455-489.

15 Kien VD, Van Minh H, Giang KB, Mai VQ, Tuan NT, Quam MB. Trends in childhood measles vaccination highlight socioeconomic inequalities in Vietnam. Int $J$ Publ Health. 2017;62(1):41-49. https://doi.org/10.1007/s00038-016-0899-4.

16 Hobcraft JN, Mcdonald JW, Rutstein SO. Socio-economic factors in Infant and child mortality: a cross-national comparison. Popul Stud. 1984;38(2):193-223. https://doi. org/10.1080/00324728.1984.10410286.

17 Braveman PA, Cubbin C, Egerter S, et al. Socioeconomic status in health research: one size does not fit all. J Am Med Assoc. 2005;294(22):2879-2888. https://doi.org/ 10.1001/jama.294.22.2879.

18 Arif A, Arif GM. Socio-economic determinants of child health in Pakistan*. Acad Res Int. 2012;2(1):398-432.

19 Amouzou A, Hill K. Child mortality and socioeconomic status in sub-Saharan Africa Afr Popul Stud. 2004;19(1):1-11.

20 Kanmiki EW, Bawah AA, Agorinya I, et al. Socio-economic and demographic determinants of under-five mortality in rural northern Ghana. BMC Int Health Hum Right. 2014;14(24). https://doi.org/10.1186/1472-698X-14-24.

21 Ayele DG, Zewotir TT, Mwambi H. Survival analysis of under-five mortality using Cox and frailty models in Ethiopia. J Health Popul Nutr. 2017;36(25). https://doi.org/ 10.1186/s41043-017-0103-3.

22 Islam MM, Azad KMAK. Rural-urban migration and child survival in urban Bangladesh: are the urban migrants and poor disadvantaged? J Biosoc Sci. 2008;40 (1):83-96. https://doi.org/10.1017/S0021932007002271.

23 Saikia N, Singh A, Jasilionis D, Ram F. Explaining the rural-urban gap in infant mortality in India. Demogr Res. 2013;29(18):473-502. https://doi.org/10.4054/ demres.2013.29.18.
24 Ghimire U, Manandhar J, Gautam A, Tuladhar S, Prasai Y, Gebreselassie T. Inequalities in Health Outcomes and Access to Services by Caste/Ethnicity, Province, and Wealth Quintile in Nepal. Rockville, Maryland, USA: ICF; 2019.

25 Cleland JG, Sathar ZA. The Effect of birth spacing on childhood mortality in Pakistan*. Popul Stud. 1984;38(3):401-418. https://doi.org/10.1080/ 00324728.1984.10410300.

26 Saabneh A. The association between maternal employment and child survival in India, 1998-99 and 2005-06. Asian Popul Stud. 2017;13(1):67-85. https://doi.org/ 10.1080/17441730.2016.1239412.

27 Shazad S. How Can Pakistan Reduce Infant and Child Mortality Rates? A Decomposition Analysis. Islamabad; 2004. https://www.sdpi.org/publications/files/W90-How Can Pakistan Reduce Infant and Child.pdf.

28 Sathar ZA. Infant and child mortality in Pakistan—some trends and differentials. J Biosoc Sci. 1985;17(3):351-360. https://doi.org/10.1017/S0021932000015820.

29 Mosley WH, Chen LC. An analytical framework for the study of child survival in developing countries. Popul Dev Rev. 1984;10:25-45.

30 Haghdoost AA. Complexity of the socioeconomic status and its disparity as a determinant of health. Int J Prev Med. 2012;3(2):75-76.

31 Shavers VL. Measurement of socioeconomic status in health disparities research. J Natl Med Assoc. 2007;99(9):1013-1023.

32 Sial MH, Noreen A, Awan RU. Measuring multidimensional poverty and inequality in Pakistan. Pakistan Dev Rev. 2015;54(4):685-698.

33 Latif A. A critical analysis of school enrollment and literacy rates of girls and women in Pakistan. Educ Stud. 2009;45(5):424-439. https://doi.org/10.1080/ 00131940903190477.

34 Isran S, Isran MA. Low female labour participation in Pakistan: causes and consequences. Pakistan J Soc Sci. 2012;33(1):163-178.

35 Pakistan Bureau of Statistics PSLM. 2014-15 Pakistan social and living standards measurement survey (2014-15). http://www.pbs.gov.pk/sites/default/files//pslm/p ublications/PSLM_2014-15_National-Provincial-District_report.pdf; 2016.

36 Saif-Ur-Rahman KM, Anwar I, Hasan M, et al. Use of indices to measure socioeconomic status (SES) in South-Asian urban health studies: a scoping review. Syst Rev. 2018;7(196):1-9. https://doi.org/10.1186/s13643-018-0867-6.

37 Rutstein SO, KJ. The DHS Wealth Index. Maryland, USA: Calverton; 2004. DHS Comparative Reports No. 6.

38 El-Ghannam AR. The global problems of child malnutrition and mortality in different world regions. J Health Soc Pol. 2003;16(4):1-26. https://doi.org/10.1300/ J045v16n04_01.

39 Cox D. Regression models and life-tables. J R Stat Soc Ser B. 1972;34(2):187-220.

40 Yu F, Yan Z, Pu R, Tang S, Ghose B, Huang R. Do mothers with lower socioeconomic status contribute to the rate of all-cause child mortality in Kazakhstan? BioMed Res Int. 2018;2:1-8. https://doi.org/10.1155/2018/3629109.

41 Grajda A, Kułaga Z, Gurzkowska B, Góźdź M, Wojtyło M, Litwin M. Trends in external causes of child and adolescent mortality in Poland, 1999-2012. Int J Publ Health. 2017. https://doi.org/10.1007/s00038-016-0908-7.

42 Naz L, Patel KK, Uzoma IE. Crucial predicting factors of under-five mortality in Sierra Leone. Clin Epidemiol Glob Heal. 2020;8(4):1121-1126. https://doi.org/10.1016/j. cegh.2020.04.002.

43 Becker GS, Lewis HG. On the interaction between the quantity and quality of children. J Polit Econ. 1973;81(2):S279-S288. https://doi.org/10.1086/260166.

44 Desai S, Jain D. Maternal employment and changes in family dynamics: the social context of women's work in rural south India. Popul Dev Rev. 1994;20(1):115-136. https://doi.org/10.2307/2137632.

45 Hussain TM, Smith JF. The relationship between maternal work and other socioeconomic factors and child health in Bangladesh. Publ Health. 1999;113(6): 299-302. 